\title{
Cobalt-Alumina Sol Gels: Effects of Heat Treatment on Structure and Catalytic Ability
}

\author{
Ryan M. Bouck ${ }^{1}$, Ann M. Anderson ${ }^{1}$, Chetna $\operatorname{Prasad}^{2}$, Michael E. Hagerman ${ }^{2}$ and Mary K. Carroll ${ }^{2, *}$ \\ ${ }^{1}$ Department of Mechanical Engineering and ${ }^{2}$ Department of Chemistry \\ Union College \\ Schenectady, NY 12308 USA \\ *corresponding author: carrollm@union.edu
}

\begin{abstract}
Cobalt-alumina $(\mathrm{Co}-\mathrm{Al})$ aerogel catalysts show potential as less expensive, sustainable alternatives to the platinum-group-metal catalysts used in three-way catalytic converters. Effects of heat treatment on the structure of $\mathrm{Co}-\mathrm{Al}$ xerogels and aerogels and catalytic performance of Co-Al aerogels were investigated. Alumina gels were prepared by epoxide-assisted sol-gel synthesis, impregnated with $\sim 3 \%$ cobalt, and either processed via rapid supercritical extraction to yield aerogels, or dried under ambient conditions to form xerogels. These materials were calcined at temperatures ranging from $400^{\circ} \mathrm{C}$ to $1100^{\circ} \mathrm{C}$ and characterized using scanning electron microscopy, energy dispersive $\mathrm{x}$-ray spectroscopy, powder $\mathrm{x}$ ray diffraction, thermogravimetric analysis and Brunauer-Emmett-Teller gas adsorption. When the aerogels and xerogels were heated to $\sim 500^{\circ} \mathrm{C}$, crystalline portions of the alumina support underwent the expected phase transformation from boehmite to $\gamma$-alumina. Aerogels resisted further changes in samples heated to $1100^{\circ} \mathrm{C}$, whereas $\gamma$-alumina in the xerogels converted to $\alpha$-alumina by $1100^{\circ} \mathrm{C}$. Heat-treated aerogels had high thermal stability, evidenced by their maintaining a surface area of $400( \pm 30) \mathrm{m}^{2} / \mathrm{g}$ after significant heating and resisting catalytically inhibiting $\theta / \alpha$-alumina phase changes. Color changes observed following heating are consistent with changes in cobalt-containing species within the materials. Preliminary catalytic tests showed that pre-heating $\mathrm{Co}-\mathrm{Al}$ aerogels to $750^{\circ} \mathrm{C}$ improves catalytic performance.
\end{abstract}

Keywords: aerogel, catalyst, three-way catalyst, alumina, cobalt-alumina, heat-treatment 


\section{INTRODUCTION}

Although many factors such as engine efficiency, gasoline quality, and vehicle design influence greenhouse gas emissions, one of the more effective ways to combat automobile pollution is through the use of three-way catalytic converters. Current catalytic converter technologies employ noble metals such as platinum and palladium on high-surface area ceramic supports [1]. Extracting and processing these metals is not only expensive but harmful to the environment. As new vehicles are produced and older vehicles are outfitted with catalytic converters, the already high demand for noble metals must increase to keep up with consumer demands, potentially posing issues for both future affordability [2] and sustainability of mining sites [3]. Thus, the development of alternate materials that have comparable catalytic activity to platinum and palladium but are relatively affordable and sustainable is a priority.

Ongoing studies have shown that transition metals and their respective oxides can act as suitable catalytic replacements for platinum and palladium [4,5]. Of particular interest are cobalt-containing compounds due to their high surface energy and reactivity, low cost, and stability over time [6]. Both cobalt catalysts and their support substrates must be able to maintain their catalytic activity and structural integrity at the high temperatures $\left(500\right.$ to $\left.600^{\circ} \mathrm{C}\right)$ of a catalytic converter. While cobalt catalysts have been embedded in substrates such as Si-doped or pure $\gamma$-alumina and tested at higher temperatures [7], these types of substrates often have had issues with decreasing hydrocarbon (HC) oxidation at higher temperatures, largely due to the $\mathrm{Co} / \mathrm{HC}$ interaction site volume decreasing as a result of various factors such as unwanted metal oxide crystallite formation [8].

An alternate type of catalyst/support material that can better meet these demands is an aerogel. Aerogels are unique nanoporous solids that are fabricated through sol-gel synthesis followed by supercritical drying to prevent the collapse of the gel matrix, keeping the expansive but delicate structure intact. The resulting matrix has many unusual properties including exceptionally high surface area and thermal stability [9], making it well suited for use as a catalytic support. Although it is possible to simply use the aerogel as a support for catalytically active species, in this work we take a different approach: 
tailoring the sol-gel chemistry to produce aerogels that are themselves catalytically active. The rapid supercritical extraction (RSCE) method employed [10,11] for fabricating aerogels that incorporate transition metal catalysts can be eco-friendly and relatively inexpensive, particularly when compared to the methods for precious metal extraction and processing.

In prior work, we have developed processes for fabricating alumina and alumina-based aerogels using the RSCE method [12-14]. Incorporation of transition metal species such as nickel, copper, cobalt and vanadium in the alumina aerogel structure have resulted in catalytically active aerogels that are structurally capable of withstanding the high temperatures in a catalytic converter's environment [14-17].

The role of the aerogel matrix and its influence on structural changes beneficial to catalysis has not yet been fully studied. In particular, understanding how the aerogel matrix interacts with the metal catalyst is critical to encouraging the formation of specific phases for targeted catalytic applications. Therefore not only heat treatment but also catalyst-support interactions can affect the physical and chemical availability of the metal catalyst sites. In this work, we focus on developing a deeper understanding of the effect of heat treatment on cobalt-alumina aerogel materials.

Heat treatment has the potential to increase the catalytic potential of the aerogel by influencing the alumina and cobalt phases in several ways. In the alumina support, heat treatment might enable conversion to $\gamma$-alumina, which is known to have catalytic activity [18]. Heat treatment could enable formation of cobalt oxides: either octahedrally arranged $\mathrm{CoO}$ or both tetrahedrally and octahedrally arranged $\mathrm{Co}_{3} \mathrm{O}_{4}$. However, the cobalt could also interact with the alumina support and form $\mathrm{CoAl}_{2} \mathrm{O}_{4}$ spinels, which have been found to undergo ionic diffusion at high temperatures where cobalt replaces aluminum in the octahedral sites, forming spinels with the structure $\mathrm{Co}_{3-s} \mathrm{Al}_{s} \mathrm{O}_{4}(0<s<2)$ [19]. $\mathrm{Because}$ cobalt is more effective as a catalyst when in octahedral sites than in tetrahedral sites [20], increasing the amount of octahedral sites will increase the overall efficiency of the catalyst. Therefore, if heat treatment can encourage the formation of $\gamma$-alumina and promote the arrangement of cobalt in octahedral sites, the catalytic activity of these aerogels would be expected to improve. 
Thus, the purpose of this study is to determine ways to optimize the catalytic potential of Co-Al based aerogels, particularly through gaining an understanding of the role of heat treatment on the phase transformations of the aerogel support matrix and metal catalyst. Co-Al aerogels were synthesized using the RSCE method $[10,14]$, heat treated at temperatures ranging from 400 to $1100^{\circ} \mathrm{C}$, and characterized using techniques such as scanning electron microscopy (SEM) to determine sample morphology, Brunauer-Emmett-Teller (BET) gas adsorption, and thermogravimetric analysis (TGA) to measure their structural stability after heating, and powder x-ray diffraction (XRD) and energy dispersive x-ray spectroscopy (EDS) to determine the composition and distribution of the catalyst and aerogel support phases. As a control, Co-Al xerogels, materials similar in structure to the aerogels but with a collapsed matrix, were also synthesized and characterized in order to better understand the interactions between the catalyst and aerogel support and the influence of the stability of the matrix. The catalytic ability of the aerogel samples was measured using a testbed apparatus and simulated automotive exhaust.

\section{EXPERIMENTAL}

\subsection{Sample Fabrication}

Cobalt-alumina (Co-Al) RSCE gels were fabricated using a modified version of an epoxide-based precursor recipe approach adapted from Baumann et al. [21] for preparation of alumina RSCE aerogels [14]. First, $2.9 \mathrm{~g}$ of aluminum nitrate hexahydrate (Fluka Analytical, 99\%) was dissolved in $20 \mathrm{~mL}$ of reagent-grade ethanol (denatured ethyl alcohol, Fisher Scientific). Then, $9.5 \mathrm{~mL}$ of propylene oxide was added, with stirring, to catalyze the gelation process. Gelation occured after approximately 3 min. The beaker containing the gel was covered with Parafilm $\mathrm{M}^{\circledR}$ and the gel was either (a) allowed to age for $24 \mathrm{~h}$ under ambient conditions, or (b) heated in a water bath at $\sim 35^{\circ} \mathrm{C}$ for $1 \mathrm{~h}$, then aged for $7 \mathrm{~h}$ under ambient conditions. The aged gel was broken into several pieces in order to facilitate the solvent exchange process. Cobalt ions were incorporated into the gel in the first solvent exchange. Excess solvent was drained from the gel and replaced with a $20-\mathrm{mL}$ solution of $0.115 \mathrm{~g}$ cobalt(II) nitrate hexahydrate (98\%, Sigma-Aldrich) in absolute ethanol (Pharmco-AAPER, Fisher Scientific) in order to impregnate cobalt 
ions into the forming alumina wet-gel matrix. The mixture was either (a) allowed to rest for $24 \mathrm{~h}$, or (b, for gels previously heated) sonicated for an hour and then allowed to rest for $7 \mathrm{~h}$. This solvent exchange process was repeated two additional times using $20 \mathrm{~mL}$ of absolute ethanol for each exchange. The resulting $\mathrm{Co}-\mathrm{Al}$ gels were processed to prepare aerogels or xerogels.

For Co-Al aerogel fabrication, after the final solvent exchange, excess solvent was drained, and the gel was placed in a closed-bottom stainless steel mold $(12.7 \times 12.7 \times 2.0 \mathrm{~cm}$ external dimensions, with four 40-mm-diameter, 1.6-cm deep wells). The excess space within the wells was filled with absolute ethanol, then the mold was sealed with stainless steel and graphite gasket, and placed in a hot press for rapid supercritical extraction (RSCE) processing [10,11]. A force of $200 \mathrm{kN}$ was applied and the mold was heated to $249{ }^{\circ} \mathrm{C}$ at a rate of $2.2{ }^{\circ} \mathrm{C} / \mathrm{min}$. Upon reaching $249{ }^{\circ} \mathrm{C}$ the system was allowed to equilibrate for 30 minutes and then the force was reduced to $4.5 \mathrm{kN}$ at a rate of $4.5 \mathrm{k} / \mathrm{min}$ and again allowed to equilibrate for 15 minutes. The final step involved cooling the mold to $38{ }^{\circ} \mathrm{C}$ at a rate of $2.2{ }^{\circ} \mathrm{C} / \mathrm{min}$. with the remaining space in each well filled with the solvent alcohol from the preparation recipe.

Co-Al xerogels were made by draining excess solvent and placing each of the gels in a beaker inside a desiccator for 2-3 days, in order to shrink the wet gel to form the collapsed matrix of a xerogel.

\subsection{Sample Preparation}

After fabrication, the aerogel samples were ground using a mortar and pestle and then more finely powdered using a coarse sifter. The particle size of these powdered samples was then standardized using a 100- $\mu \mathrm{m}$ sieve. These samples were then either set aside to be tested unheated or calcined in a Thermolyne furnace.

The samples were calcined by placing them in ceramic crucibles that were loosely covered. The crucibles were then placed in a Thermolyne furnace at room temperature; the furnace temperature was manually ramped at a rate of $200^{\circ} \mathrm{C}$ per hour until the desired temperature was reached. The samples were then held at this temperature for at least 5 hours, before being removed from the furnace and transferred 
to another crucible to quickly cool off in open air. Samples were heated to temperatures ranging from $400^{\circ} \mathrm{C}$ to $1100^{\circ} \mathrm{C}$.

\subsection{Sample Characterization}

Changes in the morphology of the aerogel structure were observed through scanning electron microscopy (SEM) using a Zeiss EVO50 scanning electron microscope. Samples were prepared for imaging by lightly dusting powdered $\mathrm{Co}-\mathrm{Al}$ aerogel on carbon tape attached to aluminum sample holders. Before imaging, the samples were sputter coated for 30 seconds using a Denton Vacuum Desk IV Sputter Coater with a gold/palladium target. Cobalt-containing regions and the overall cobalt distribution in the sample were investigated by electron-dispersive spectroscopy (EDS) alongside SEM imaging. For EDS mapping, the SEM was set to have a spot size of $550 \mathrm{~nm}$, a working distance that ranged between 13-20 $\mathrm{mm}$, and variable $\mathrm{keV}$ generally in the range of $8 \mathrm{kV}-15 \mathrm{kV}$.

Changes in the bonding and crystal structure were measured through powder X-ray diffraction (XRD) using a Phillips PW-1840 X-ray diffraction instrument employing a Co-K $\alpha(\lambda=1.79 \mathrm{~nm})$ radiation source. Samples were prepared for testing by firmly pressing powdered sample into the center of a zerodiffraction silicon sample holder. Samples were measured at a voltage of $45 \mathrm{keV}$ and a current of $35 \mathrm{~mA}$. Spectra were taken by setting the goniometer to move $0.06^{\circ} / \mathrm{min}$ over the interval of $2 \theta=20^{\circ}$ to $85^{\circ}$.

Surface area was measured through BET gas adsorption testing using a Micrometrics TriStar 3000 surface area and porosity analyzer. Approximately $0.15 \mathrm{~g}$ of aerogel sample was used for each test. The samples were degassed at $90^{\circ} \mathrm{C}$ for one hour and then at $200^{\circ} \mathrm{C}$ for at least four hours before testing. After degas, the samples were re-massed and analyzed on the Tristar. BET surface areas were estimated using measurements at 5 partial pressures between 0.05 and 0.3 with an equilibration time of 20 seconds.

The effects of dehydration on the alumina structure were studied through thermogravimetric analysis (TGA) using a Perkin-Elmer TGA-7 analyzer. Approximately $2.5 \mathrm{mg}$ of sample was pretreated at an equilibrium temperature of $50^{\circ} \mathrm{C}$ for 4 minutes and then tested over a range from $50-800^{\circ} \mathrm{C}$ for 1 hour. 


\subsection{Catalytic Characterization}

Preliminary catalytic studies were performed on the cobalt-alumina aerogels using the Union College Catalytic Testbed [17], which is designed to flow custom gas blends through a cylindrical test section at a range of temperatures from $350-750^{\circ} \mathrm{C}$. The aerogel samples were crushed to a coarse powder and $1-2 \mathrm{~g}$ were placed in the $20 \mathrm{~mL}$ test section. A blend of $200 \mathrm{ppm} \mathrm{C}_{3} \mathrm{H}_{8}, 0.5 \% \mathrm{CO}, 6 \% \mathrm{CO}_{2}, 300 \mathrm{ppm} \mathrm{NO}$ (with $\mathrm{N}_{2}$ as the balance) mixed with compressed air at a 0.017:1 air-to-blend ratio ( 1.7\% air) was used to simulate automotive exhaust. Tests were run using a space velocity of $20 \mathrm{~s}^{-1}$ and an EMS Model 8000 exhaust gas analyzer was used to measure the concentrations of hydrocarbons (propane), carbon monoxide, carbon dioxide, nitrogen oxides, and oxygen downstream of the test section. Conversion rates were calculated as the difference between initial bottle and downstream concentrations.

\subsection{Error Estimates in Measured Values}

Uncertainty estimates for each variable were determined by repeat measurements or based on instrument specifications, as detailed in our previous work describing the preparation of epoxide-assisted alumina aerogels by RSCE [14].

\section{RESULTS}

\subsection{Sample Appearance: As-prepared and Heated Aerogels and Xerogels}

The Co-Al aerogels produced by this method were bright blue in color (see Figure 1a). Samples heated past $480^{\circ} \mathrm{C}$ underwent a color change to lavender (Figure 1b), likely indicating a structural change. Samples heated past $650^{\circ} \mathrm{C}$ turned a shade of deep indigo, which continued to deepen in color with additional heating up to $750^{\circ} \mathrm{C}$ (see Figure 1c). Samples heated past $900^{\circ} \mathrm{C}$ changed color to a bright cerulean blue (Figure 1d). This color is observed up to $1100^{\circ} \mathrm{C}$, the highest temperature to which the aerogels were heated. 
For comparison, the colors of heat-treated Co-Al xerogels were also observed (Figures 1e-h). Asprepared xerogels were non-uniform in color; some pieces appeared indigo, others were clear and colorless (Figure 1e). FTIR and XRD spectra of the differently colored portions of the gels (not included here) showed that all contained boehmite-phase alumina. Thus, the dual coloration was likely a result of unevenly distributed cobalt in the structure. When heated, the clear, colorless xerogel pieces underwent a series of color changes: they were orange at $480^{\circ} \mathrm{C}$ (Figure 1f), white at $600^{\circ} \mathrm{C}$ (not shown), blue-ish at $1000^{\circ} \mathrm{C}$ (Figure 1g), and pale blue at $1100^{\circ} \mathrm{C}$ (Figure 1h). The xerogel pieces that were initially indigo in color also underwent color changes at elevated temperature, becoming brighter blue at temperatures above $600^{\circ} \mathrm{C}$ (Figure 1g) and pale blue color at $1100^{\circ} \mathrm{C}$ (Figure $1 \mathrm{~h}$ ).

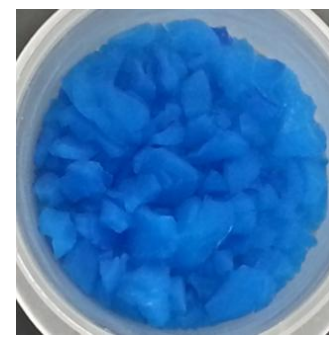

(a) unheated

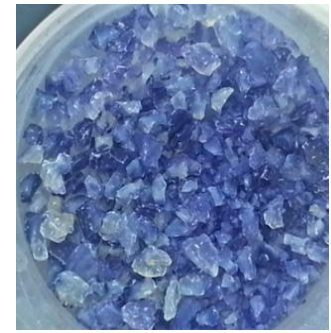

(e) unheated

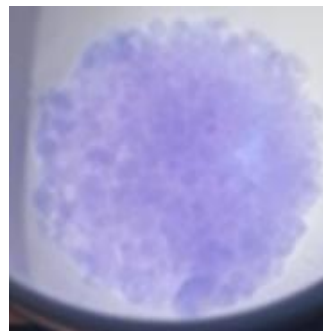

(b) $480^{\circ} \mathrm{C}$

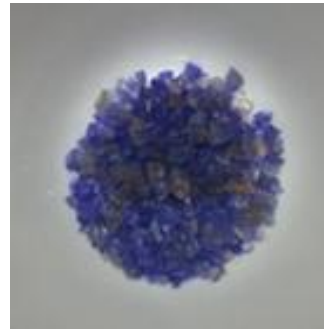

(f) $480^{\circ} \mathrm{C}$

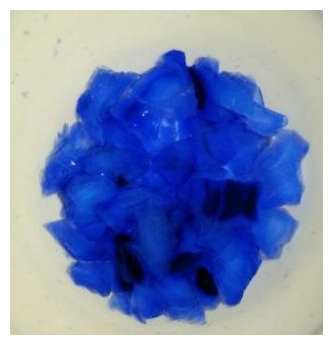

(c) $750^{\circ} \mathrm{C}$

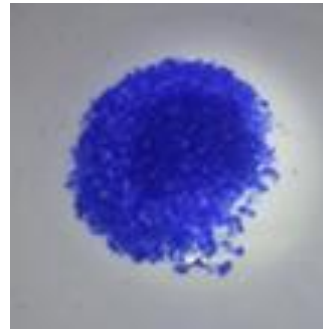

(g) $1000^{\circ} \mathrm{C}$

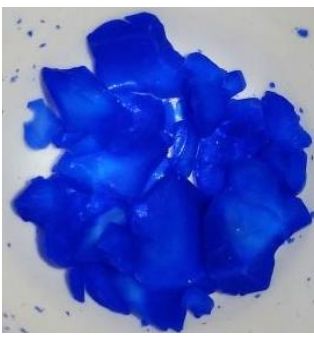

(d) $900^{\circ} \mathrm{C}$

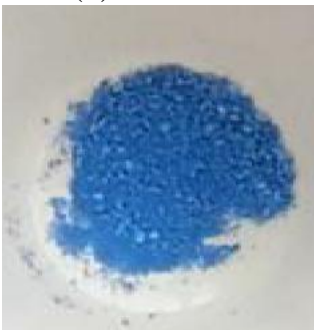

(h) $1100^{\circ} \mathrm{C}$

Figure 1. Photographs of aerogel and xerogel samples: (a) Unheated Co-Al aerogel sample (b) Co-Al aerogel sample heated to $480^{\circ} \mathrm{C}$ (c) Co-Al aerogel sample heated to $750^{\circ} \mathrm{C}$ (d) $\mathrm{Co}-\mathrm{Al}$ aerogel sample heated to $900^{\circ} \mathrm{C}$ (e) Unheated $\mathrm{Co}-\mathrm{Al}$ xerogel sample (f) $\mathrm{Co}-\mathrm{Al}$ xerogel sample heated to $480^{\circ} \mathrm{C}$ (g) $\mathrm{Co}-\mathrm{Al}$ xerogel sample heated to $1000^{\circ} \mathrm{C}$ (h) Co-Al xerogel sample heated to $1100^{\circ} \mathrm{C}$.

\subsection{XRD Results: As-prepared and Heated Aerogels and Xerogels}

The alumina backbone of the Co-Al aerogels is largely amorphous and the cobalt content of the materials is relatively low (ca. 5\%); thus, signal-to-noise ratios for observed peaks in the XRD spectra 
were anticipated to be low. However, in studies by Oliveira et al. [22] and Abad-Elwahad et al. [23], $\mathrm{XRD}$ peaks for cobalt species were detected in materials with as low as $3 \% \mathrm{Co}$, which is comparable to the loading in our samples.

XRD spectra of unheated aerogels (Figure 2a) show evidence of crystallized boehmite structures [24] at $2 \theta=27^{\circ}, 49.6^{\circ}$, and $64^{\circ}$. These materials lose crystallinity beginning at $400^{\circ} \mathrm{C}$ and show evidence of a phase transition starting around $525^{\circ} \mathrm{C}$ (Figure 2a). Peaks attributable to $\gamma$-alumina [25] were observed for samples heated to $700^{\circ} \mathrm{C}$ (Figure 2a), evidenced by peaks at $2 \theta=37^{\circ}, 46^{\circ}$, and $66.5^{\circ}$ As the sample was heated from $700^{\circ} \mathrm{C}$ to $1100^{\circ} \mathrm{C}$, the amount of $\gamma$-alumina increased, as seen in the increasing intensity of these $\gamma$-alumina peaks and the appearance of additional $\gamma$-alumina peaks at $2 \theta=32^{\circ}$ and $61^{\circ}$. There was no evidence of conversion to $\alpha$-alumina or any transitional $\theta$-alumina phases, as typically seen at these temperatures in bulk alumina structures [26].

The small peaks detected upon heating to $700^{\circ} \mathrm{C}$ could provide evidence of formation of microcrystalline cobalt-containing species; however, we note that the signal-to-noise ratio is very low. Moreover, peaks corresponding to $\mathrm{CoO}, \mathrm{Co}_{3} \mathrm{O}_{4}$, and $\mathrm{CoAl}_{2} \mathrm{O}_{4}$ are difficult to differentiate from each other using XRD spectra due to their significant peak overlap. Here, we have considered the temperatureinduced color changes when interpreting the XRD spectra. The peaks at $2 \theta=36^{\circ}$ and $62^{\circ}$ are consistent with $\mathrm{CoO}$ (as in Glaspell et al., 2004 [27]), and the peak at $2 \theta=44^{\circ}$ with $\mathrm{Co}_{3} \mathrm{O}_{4}$ (as in Kim et al., 2012 [28]). As the sample was heated from $700-1100^{\circ} \mathrm{C}$, peaks at $2 \theta=32^{\circ}, 36^{\circ}, 44^{\circ}$, and $59^{\circ}$ increased in intensity, suggesting the formation of more stable species, either $\mathrm{Co}_{3} \mathrm{O}_{4}$ or $\mathrm{CoAl}_{2} \mathrm{O}_{4}$, with increasing temperature.

As a comparison, XRD spectra of Co-Al xerogels are included in Figure 2b. The xerogel samples were predominantly amorphous at lower temperatures, with unheated samples exhibiting some evidence of crystallized boehmite (see Figure $2 \mathrm{~b}$ ). Upon heating to $900^{\circ} \mathrm{C}$, the xerogels show some evidence of $\gamma$ alumina formation. Conversion to $\alpha$-alumina was observed around $1100^{\circ} \mathrm{C}$. 


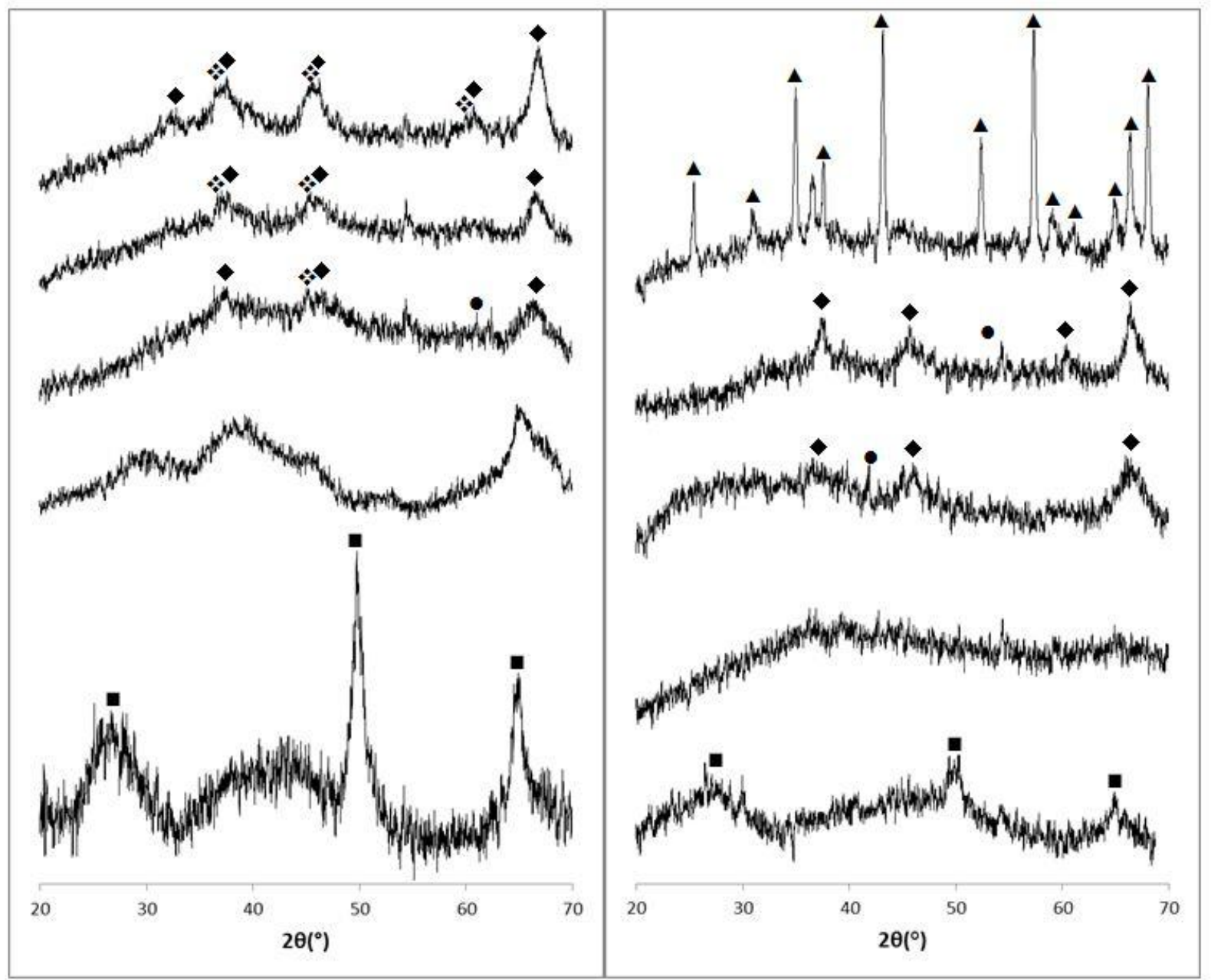

(a)

(b)

Figure 2. XRD spectra for heat-treated Co-Al aerogels $(a)$ and xerogels $(b)$ shown in order of increasing temperature from unheated to $525^{\circ} \mathrm{C}$ to $700^{\circ} \mathrm{C}$ to $900^{\circ} \mathrm{C}$ to $1100^{\circ} \mathrm{C}$ (from bottom to top respectively) taken from $2 \theta=$ $20-85^{\circ}$ using a Co target (values converted to a $\mathrm{Cu}$ target for plotting). Plots were scaled to the same relative intensity. Corresponding boehmite peaks are designed by $\mathbf{\square} \gamma$-alumina peaks are designated by $\boldsymbol{\nabla} ; \boldsymbol{\alpha}$-alumina by $\boldsymbol{\Delta}$; $\mathrm{CoO}$ by $\bullet$; and $\mathrm{Co}_{3} \mathrm{O}_{4}$ and $\mathrm{CoAl}_{2} \mathrm{O}_{4}$ by . The peak observed at $54^{\circ}$ is an artifact from the sample holder.

\subsection{Thermal Stability - TGA Results}

TGA data for the Co-Al aerogel and xerogel are shown in Figure 3. The Co-Al aerogel shows a gradual $5 \%$ weight loss when heated to $350^{\circ} \mathrm{C}$, which is attributable to the breakdown and removal of solvents, including unbound water, in the sample. From $350^{\circ} \mathrm{C}$ to $525^{\circ} \mathrm{C}$, an additional $13 \%$ weight loss occurred indicating the removal of bound water in the alumina structure, consistent with the phase 
transformation from boehmite to $\gamma$-alumina observed in the XRD data. The weight loss continued until $850^{\circ} \mathrm{C}$, suggesting that bound water was removed from the structure with additional heating. This conclusion is supported by the increasing intensities of $\gamma$-alumina peaks seen in the XRD spectra. The overall weight loss of the aerogel sample was found to be about $25 \%$.

For the xerogel samples, the slope of the temperature profile curve was significantly steeper throughout the entire interval, suggesting that the xerogel was less thermally stable than the aerogel. The overall weight loss of the xerogel sample was found to be $37 \%$.

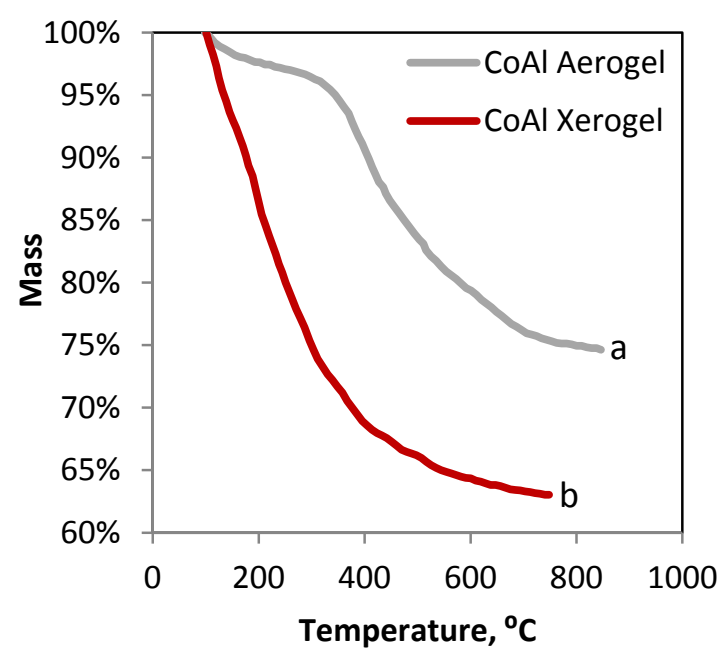

Figure 3. TGA plots for $\mathrm{Co}-\mathrm{Al}$ (a) aerogel and (b) xerogel samples.

\subsection{Surface Area Results: As-prepared and Heated Aerogels}

The effect of heat treatment on the BET surface area of the Co-Al aerogels is shown in Figure 4. Unheated Co-Al aerogel samples had a surface area of $700( \pm 30) \mathrm{m}^{2} / \mathrm{g}$ (not shown). The surface area of the aerogels was not observed to change significantly until the aerogels were heated above $425^{\circ} \mathrm{C}$. 


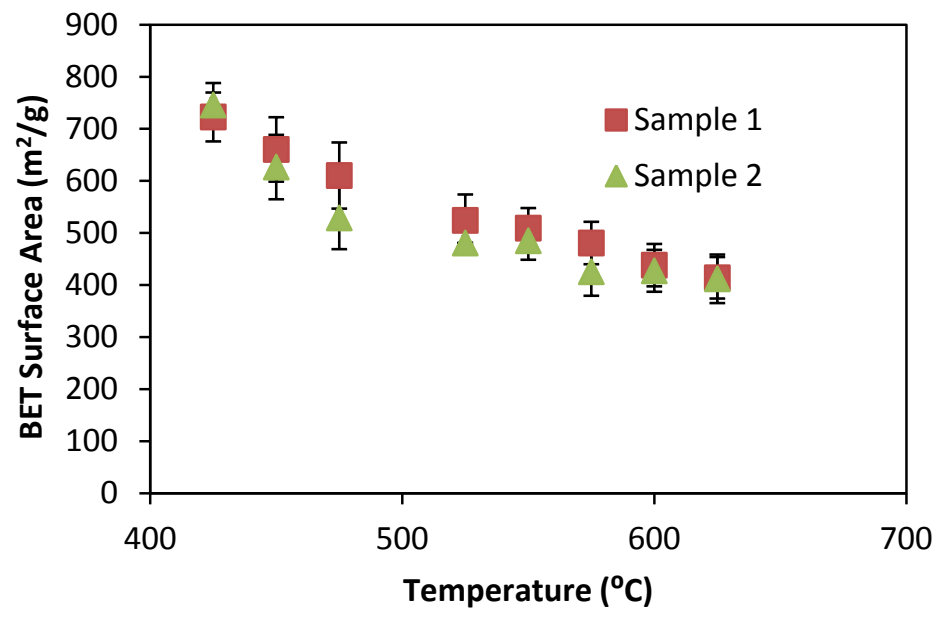

Figure 4. BET gas adsorption surface area plot for $\mathrm{Co}-\mathrm{Al}$ aerogel samples heated from 400 to $625^{\circ} \mathrm{C}$. Error bars represent the combined uncertainty in the BET fit and in the sample mass measurement.

\subsection{SEM Results: As-prepared and Heated Aerogels}

SEM imaging showed that the Co-Al aerogels consisted of a fine, fibrous matrix with features in the range of $50-100 \mathrm{~nm}$ as prepared or when heated to moderate temperatures (Figure $5 \mathrm{a}$ ). Above $480^{\circ} \mathrm{C}$, it appeared that the structure began to densify (Figure 5b), shifting away from a fine matrix to clusters of agglomerated particles, which became more pronounced as the sample was heated past $525^{\circ} \mathrm{C}$ (Figure $5 \mathrm{c}$ ).

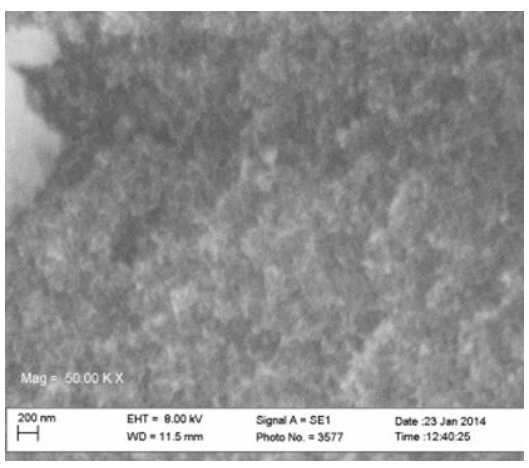

(a)

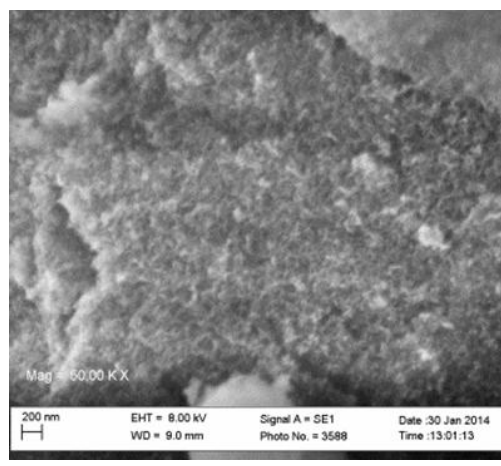

(b)

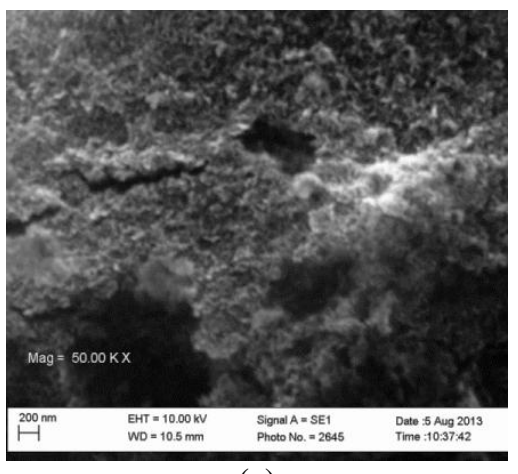

(c)

Figure 5. SEM images of $\mathrm{Co}-\mathrm{Al}$ aerogels at approximately 50k magnification shown in order of increasing temperature: (a) heated to $400^{\circ} \mathrm{C}$ (b) heated to $500^{\circ} \mathrm{C}$ (c) heated to $525^{\circ} \mathrm{C}$. All samples were sputter coated prior to imaging.

FIB-SEM images (Figure 6) of a catalytically tested Co-Al aerogel (heated to $700^{\circ} \mathrm{C}$ ) confirmed the presence of the fibrous alumina morphology seen in the SEM. 


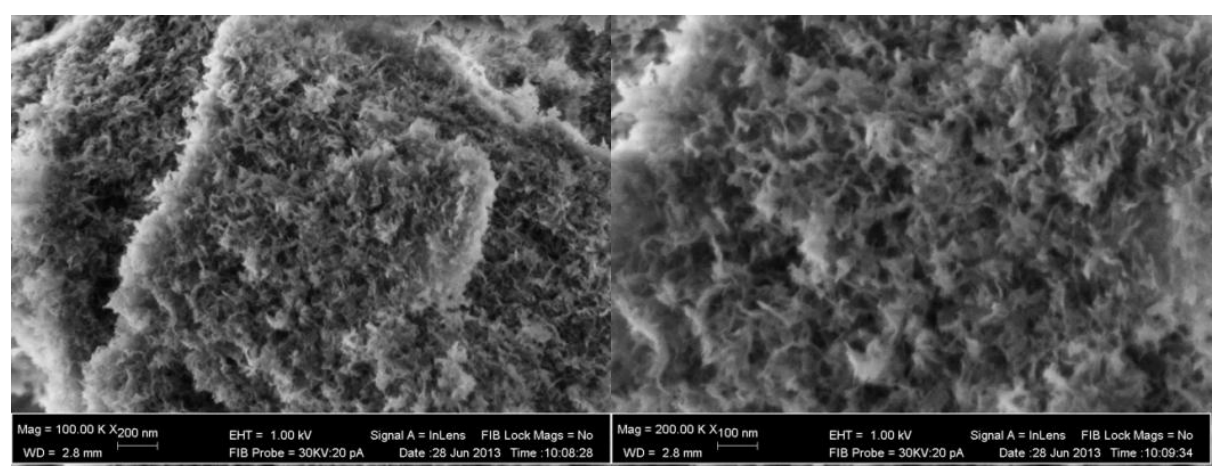

(a)

(b)

Figure 6. FIB-SEM images of catalytically tested $\mathrm{Co}-\mathrm{Al}$ aerogels (heated to $700^{\circ} \mathrm{C}$ ) at approximately (a) $100 \mathrm{~K}-\mathrm{X}$ magnification (b) and 200K-X magnification.

In EDS spectra of unheated Co-Al aerogel shown in Figure 7, cobalt did not appear to be concentrated within crystallites, but instead appeared to be distributed in areas with high $\mathrm{Al}$ and $\mathrm{O}$ signals, suggesting that cobalt was incorporated within the alumina structure.

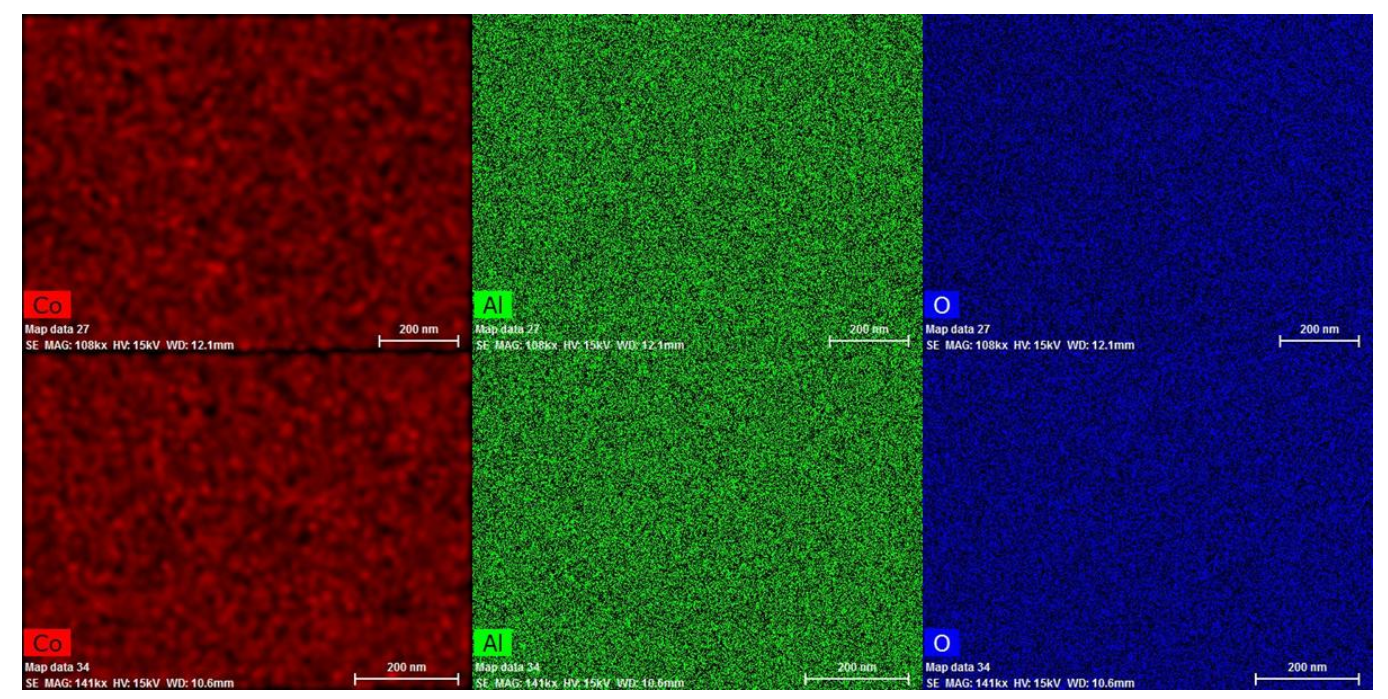

Figure 7. EDS mapping of $\mathrm{Co}, \mathrm{Al}$, and $\mathrm{O}$ in unheated $\mathrm{Co}-\mathrm{Al}$ aerogel (top) and catalytically tested $\mathrm{Co}-\mathrm{Al}$ aerogel (bottom)

\subsection{Catalytic Potential - Preliminary Catalytic Testing Results}

Co-Al aerogels show significant catalytic activity (Figure 8). Testing was done both with (oxidizing environment) and without (reducing environment) air to simulate the fuel rich/fuel lean conditions in a real catalytic converter. 

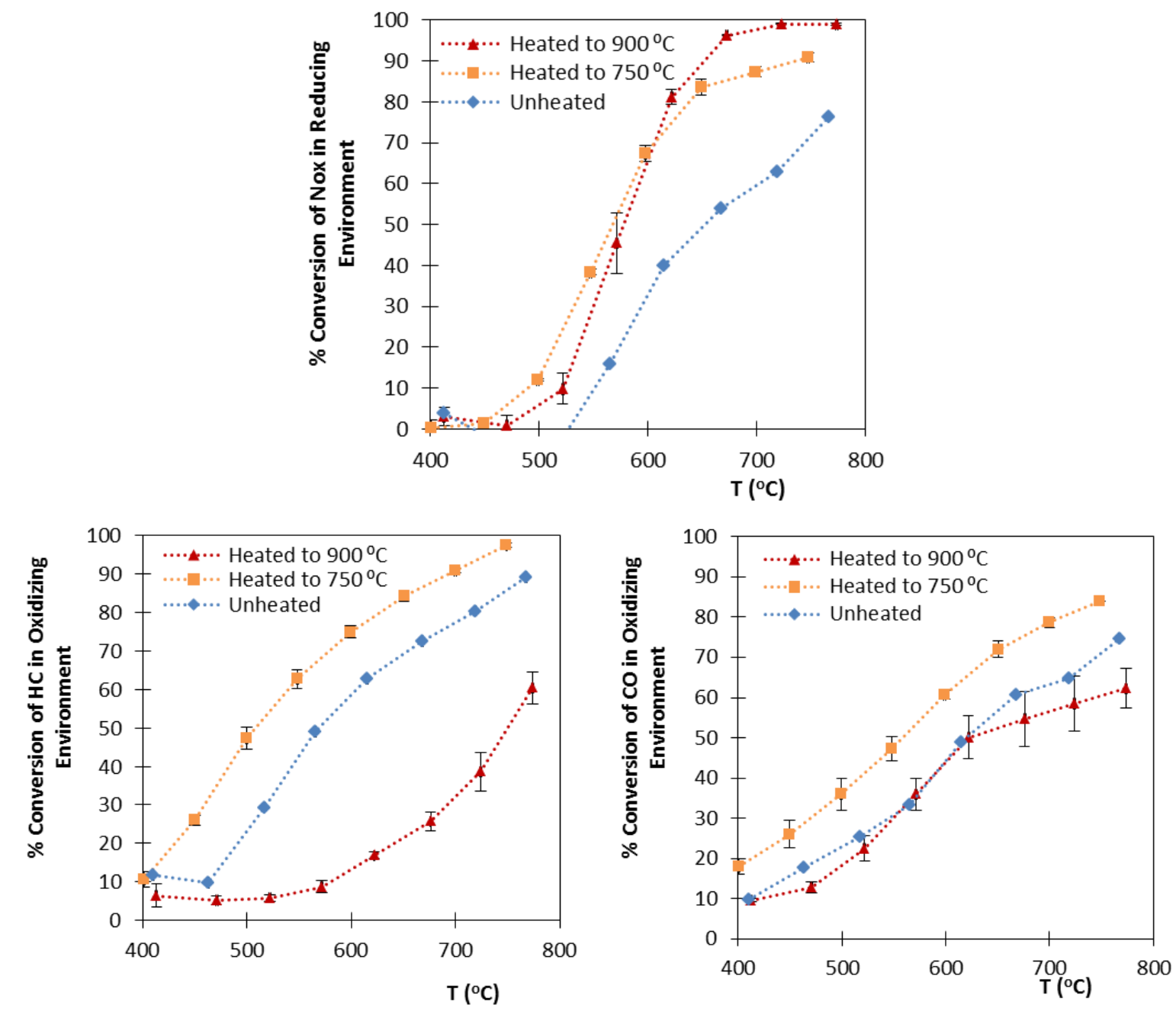

Figure 8. Results of catalytic testing for $\mathrm{Co}-\mathrm{Al}$ aerogels. Blue diamonds represent the results of the first catalytic test for as-prepared aerogels. Results for aerogel samples heat-treated to $750^{\circ} \mathrm{C}$ (yellow squares) and $900^{\circ} \mathrm{C}$ (red triangles) prior to testing are plotted as average \pm one standard deviation. Percent conversion of (a) $\mathrm{NO}_{\mathrm{x}}$ in a reducing environment, (b) HCs (propane) in an oxidizing environment and (c) percent conversion of $\mathrm{CO}$ in an oxidizing environment, are plotted as a function of temperature.

As-prepared aerogels show significant catalytic activity (Figure 8), with light off (50\% conversion) observed for $\mathrm{NO}_{\mathrm{x}}$ below $700^{\circ} \mathrm{C}$, for $\mathrm{HCs}$ below $600^{\circ}$, and for $\mathrm{CO}$ around $625^{\circ} \mathrm{C}$. In subsequent tests, the catalytic performance of these samples was observed to improve, with light off achieved at lower temperatures. Thus, the heating experienced during catalytic testing resulted in changes in the catalytic performance. Heat-treating the aerogels to $750^{\circ} \mathrm{C}$ (the highest temperature employed in these catalytic tests), prior to catalytic testing lowered the light-off temperatures to $550^{\circ} \mathrm{C}$ for $\mathrm{NO}_{\mathrm{x}}, 500^{\circ} \mathrm{C}$ for $\mathrm{HCs}$ and $550^{\circ} \mathrm{C}$ for $\mathrm{CO}$, and resulted in higher overall conversion of all three gases, with consistent results 
observed in repeated tests. Heat-treating to $900^{\circ} \mathrm{C}$ resulted in modest improvement in $\mathrm{NO}_{\mathrm{x}}$ conversion but significantly degraded performance for the HCs and moderately lowered performance for CO.

\section{DISCUSSION}

Blue coloration in cobalt compounds generally indicates tetrahedral bonding, whereas pinkish-red indicates octahedral bonding [29]. The observed color changes provide evidence for structural changes in the cobalt catalyst phase, in both the aerogel and xerogel samples. An initial change from blue to violet (seen in Figures $1 \mathrm{a} \& \mathrm{lb}$ ) could indicate the formation of octahedrally coordinated $\mathrm{CoO}$ and $\mathrm{Co}_{3} \mathrm{O}_{4}$ and the black residue seen around $750^{\circ} \mathrm{C}$ could also be evidence of $\mathrm{Co}_{3} \mathrm{O}_{4}$ [30]. At higher temperatures, both $\mathrm{CoO}$ and $\mathrm{Co}_{3} \mathrm{O}_{4}$ would be expected to break down, allowing free cobalt ions to integrate into the alumina structure, in which case the samples would be expected to shift to a bluer color, which was also observed (Figures $1 \mathrm{~b} \& \mathrm{c}$ ). This change could be due to the formation and development of cobalt alumina spinel $\left(\mathrm{CoAl}_{2} \mathrm{O}_{4}\right)$ phase, which is known to have a bright blue color that increases in intensity with heating [31]. A transition to brighter shades of blue was evident in heating the aerogel sample past $900^{\circ} \mathrm{C}$ (Figures $1 \mathrm{c} \&$ 1d).

Aerogel and xerogel matrices produce significantly different crystal phases as heated. At lower temperatures, aerogels show more evidence of crystal growth whereas xerogels remained relatively amorphous. At higher temperatures, aerogels resisted crystal growth; xerogels became more crystalline. Transitions from boehmite to $\gamma / \eta$-alumina consist of rearrangements in the structure, whereas transitions from $\gamma$-alumina to $\theta$ - and $\alpha$-alumina consist of mass agglomeration of the grain boundaries in the structure [32]. When Co-Al aerogels and xerogels were heated, the alumina matrix underwent the expected phase transformation from boehmite to $\gamma$-alumina (Figure 2). The aerogel sample resisted further changes, remaining in the $\gamma$-alumina phase up to $1100^{\circ} \mathrm{C}$ (Figure 2a), whereas the xerogel sample converted to $\alpha$ alumina (Figure $2 b$ ). The aerogel matrix likely impedes the formation of $\theta$ - or $\alpha$-alumina at higher temperatures by restricting movement of $\mathrm{Al}$ in the structure (preventing grain boundaries from making 
contact with each other). The xerogel matrix behaves more like bulk alumina. Fully crystalline $\gamma$-alumina would have been expected in a bulk alumina sample as the boehmite phase dehydrated and agglomerated [33]. The xerogel matrix is unable to restrict the agglomeration of the alumina particles and is less thermally stable as a consequence, resulting in formation of $\alpha$-alumina, which has much lower surface area and catalytic activity [34]. These results are consistent with the work by Suh et al., who compared the crystalline growth in heated alumina-based aerogels and xerogels and found weaker phase transformations in the aerogels [9].

Because of the low concentration of cobalt, the XRD results are less conclusive. There is some evidence of $\mathrm{CoO}, \mathrm{Co}_{3} \mathrm{O}_{4}$ and $\mathrm{CoAl}_{2} \mathrm{O}_{4}$ spinel formation (Figure 2a); however, the relevant peaks are near the limit of detection. Although $\mathrm{Co}_{3} \mathrm{O}_{4}$ and $\mathrm{CoAl}_{2} \mathrm{O}_{4}$ are almost indistinguishable from each other in XRD spectra $[28,35]$, the shift from a violet to bright blue color characteristic of the cobalt aluminate spinel with increasing temperature suggests the formation of the spinel phase.

The TGA results for Co-Al aerogel (Figure 3) suggest that the boehmite phase is dehydrating and consequently undergoing a phase transformation to $\gamma$-alumina, which is also evidenced in the XRD spectra for the sample heated to $525^{\circ} \mathrm{C}$ (Figure 2a). The initial dehydration of the alumina structure is governed by three components: (1) hydrogen bond rearrangement, (2) water removal, and (3) aluminum ion rearrangement [33]. The dehydration of the structure enables the first phase transformation by satisfying conditions (1) and (2). Water removal likely does not occur uniformly but in pockets, where both dehydration and consequently localized pore collapse occur. The lack of thermal stability for the xerogels (Figure 3 ) is consistent with the results seen in the XRD data (Figure 2b): the xerogels appear to be prone to dehydration and consequently $\gamma$-alumina growth. It is also possible that the xerogel contained more adsorbed solvent at the start of the analysis than did the aerogel, contributing to the higher observed overall loss in mass.

After heating to higher temperatures, significant decreases in surface area were observed (Figure 4).. These observed changes could be the result of continuous pore collapse associated with bound water 
leaving the structure and the unrestrained alumina densifying, reducing the surface area. Wang et al. have shown that the estimated weight loss due to complete alumina dehydration and loss of bound water due to boehmite conversion is approximately $15 \%$ [36], which agrees with the TGA results (total weight loss of $13 \%$ upon heating from $350^{\circ} \mathrm{C}$ to $600^{\circ} \mathrm{C}$ ). Note that even after heating above $600^{\circ} \mathrm{C}$, surface areas were $>400 \mathrm{~m}^{2} / \mathrm{g}$, indicative of aerogel structures; this property renders the materials attractive for catalytic applications.

The observed structural change observed in SEM (Figures 5 and 6) could be due to localized dehydration and pore collapse, and is consistent with the TGA results. Localized cobalt-containing particles were not observed in EDS (Figure 7); however, to be detected at the resolution of the available SEM, any cobalt oxide particles formed would have had to be at least tens of nanometers in size. Thus, if the small peaks observed in the XRD spectra are due to $\mathrm{Co}_{3} \mathrm{O}_{4}$ formation (Figure 2a), the crystallites must be in a highly dispersed nanoscale phase.

These aerogels appear to be functioning as three-way catalysts (Figure 8), albeit at higher light-off temperatures than is typical for commercial TWCs [37]. For Co-Al aerogels preheated to $750^{\circ} \mathrm{C}$ prior to catalytic testing, light-off temperatures of $500-550^{\circ} \mathrm{C}$ and percent conversion of $80-90+\%$ was observed. Heat-treatment to $900^{\circ} \mathrm{C}$ prior to testing resulted in an enhancement in $\mathrm{NO}_{\mathrm{x}}$ conversion but poorer performance with respect to $\mathrm{HCs}$ and $\mathrm{CO}$, indicating structural change occurred in the catalyst.

The data presented here were sufficient to establish the experimental conditions for heat-treatment of Co-Al aerogels prior to catalytic testing. Extending TGA measurements to higher temperatures or recording high-temperature XRD spectra (neither of which is possible with instrumentation available at our institution) would yield additional insight as to the specific temperatures at which the observed structural changes occur in the $\mathrm{Co}-\mathrm{Al}$ aerogels and xerogels.

In this study, the fabrication of the aerogels (variations in precursor recipe, including amount of cobalt salt employed, and processing conditions) has not been optimized. Moreover, performance of the aerogels under conditions that include humidity has not been evaluated. Reproducibility was good for several 
repeat measurements; however, the long-term catalytic performance of the $\mathrm{Co}-\mathrm{Al}$ aerogels has not been evaluated. These are areas of ongoing research activity in our laboratory.

\section{CONCLUSIONS}

Cobalt-alumina aerogels were successfully fabricated by the RSCE method and characterized as prepared and following heat treatment. The observed color changes, XRD spectra and TGA results provide evidence for structural changes in the alumina support matrix and cobalt catalyst phase, in both the aerogel and xerogel samples. Results of catalytic testing demonstrate the promise of Co-Al aerogel materials for applications as three-way catalysts for automotive pollution mitigation. Untreated Co-Al aerogels exhibited substantial catalytic activity, with $\%$ conversions of $>70 \%$ for propane, $\mathrm{CO}$ and $\mathrm{NO}$; heat treatment of aerogels to $750^{\circ} \mathrm{C}$ prior to catalytic testing resulted in increased conversion.

From the SEM images, it can be seen that as-prepared Co-Al aerogels had a nanoporous structure. XRD confirmed that the aerogel included crystallites in boehmite phase. As the samples were heated, the structure began to densify, evidenced by agglomerated regions that became more plentiful with further heating. When both the aerogels and the xerogels were heated, crystalline portions of the alumina support underwent the expected phase transformation from boehmite to $\gamma$-alumina. The aerogel sample resisted further changes, with evidence of $\gamma$-alumina remaining in samples heated to $1100^{\circ} \mathrm{C}$, whereas the $\gamma$ alumina in the xerogel sample converted to $\alpha$-alumina by $1100^{\circ} \mathrm{C}$.

The formation and development of $\gamma$-alumina likely contributed to the improved catalytic performance for aerogels heat-treated to $750^{\circ} \mathrm{C}$ prior to analysis. In previous work, we demonstrated that alumina aerogels exhibited modest catalytic activity [14]; however, the catalytic performance of the Co-Al aerogels described in the present work was significantly higher. We therefore conclude that the cobalt species in the aerogel are a significant source of catalytic activity. Different cobalt site arrangements can have different effects on influencing catalytic activity, and, in general, octahedrally arranged species are more effective than tetrahedral counterparts in cobalt containing compounds [38,39]. XRD results suggest that tetrahedrally and octahedrally arranged $\mathrm{Co}_{3} \mathrm{O}_{4}$ might have been formed at lower temperatures. 
Unfortunately, because the concentration of cobalt in the aerogels is relatively low and the aerogel is largely amorphous, it is not possible to unambiguously assign cobalt species. The various color changes observed following heating of the Co-Al samples are consistent with changes in cobalt-containing species within the aerogel. Prior work by others with cobalt alumina aerogel spinels has shown that $\mathrm{Co}_{3} \mathrm{O}_{4}$ was the dominant oxide formed when a nitrate salt was used in the initial precursor mixture [40]. Some evidence of this oxide phase was seen in the XRD spectra. It is plausible that $\mathrm{Co}_{3} \mathrm{O}_{4}$ was decomposed after heating due to its high degree of reducibility [41] and the free cobalt began to integrate within the alumina structure forming a spinel. Other studies have supported this idea, seeing cobalt spinels form in Co-Al aerogels after heat treatment [42], particularly in high surface area substrates with strong metalsupport interactions [41].

These conclusions are also supported by the catalytic data. Cobalt aluminate spinels have been shown to have high activity in catalyzing $\mathrm{NO}_{\mathrm{x}}$ [43], whereas $\mathrm{CoO}$ and $\mathrm{Co}_{3} \mathrm{O}_{4}$ have been shown to be more effective in catalyzing $\mathrm{CO}[39,41,44]$. From the color changes and XRD data, $\mathrm{CoO}$ and $\mathrm{Co}_{3} \mathrm{O}_{4} \operatorname{could}_{\text {be }}$ present in $\mathrm{Co}-\mathrm{Al}$ aerogels heated to $750^{\circ} \mathrm{C}$ whereas a cobalt aluminate spinel might form around $900^{\circ} \mathrm{C}$. This interpretation correlates with the increase in $\mathrm{NO}_{\mathrm{x}}$ conversion and decrease in $\mathrm{CO}$ conversion for predominantly cobalt aluminate spinel containing Co-Al aerogels pretreated to $900^{\circ} \mathrm{C}$ as well as the lower $\mathrm{NO}_{x}$ but significantly higher $\mathrm{CO}$ conversion for predominately $\mathrm{Co}_{3} \mathrm{O}_{4}$ containing $\mathrm{Co}-\mathrm{Al}$ aerogels pretreated to $750^{\circ} \mathrm{C}$.

Overall, cobalt-alumina aerogels show promise as a lower-cost, more sustainable alternative to platinum group metals in catalytic converters.

\section{ACKNOWLEDGEMENTS}

This material is based upon work supported by the National Science Foundation (NSF) under Grants No. DMR-1206631 and CBET-1228851. The authors thank David M. Frey for FIB-SEM imaging of Co$\mathrm{Al}$ aerogel, Isaac Ramphal for obtaining the catalytic test bed data for the different heat treated Co-Al samples, and Caroline Gorka, Travis Barker, Aude Bechu, and Samuel Kleinberg for making aerogel and 
xerogel samples used in this study. The SEM used for this study was funded by New York State Assembly - RESTORE-NY and NSF EAR 0619578. The authors thank the Union College Geology Department for use of the XRD instrument. RMB thanks Union College for a Summer Undergraduate Research Fellowship and Student Research Grant funding.

\section{REFERENCES}

[1] Golunski, S. Gas-phase catalysis by platinum-group metals - past, present, and future. JOM 2009, 53, $22-24$.

[2] Yang, C-J. An impending platinum crisis and its implications for the future of the automobile. Energy Policy 2009, 37, 1805-1808.

[3] Glaister, B.J.; Mudd, G.M. The environmental costs of platinum-PGM mining and sustainability: Is the glass half-full or half-empty? Miner. Eng. 2010, 23, 438-450.

[4] Bashyam, R.; Zelenay, P. A class of non-precious metal composite catalysts for fuel cells. Nature 2006, 443, 63-66.

[5] Suntivich, J.; Gasteiger, H.A.; Yabuuchi, N.; Nakanishi, H.; Goodenough, J.B.; Shao-Horn, Y. Design principles for oxygen-reduction activity on perovskite oxide catalysts for fuel cells and metal-air batteries. Nat. Chem. 2011, 3, 546-550.

[6] Zhang, G.; Scott, B. L.; Hanson, S. K. Mild and Homogeneous Cobalt-Catalyzed Hydrogenation of $\mathrm{C}=\mathrm{C}, \mathrm{C}=\mathrm{O}$, and $\mathrm{C}=\mathrm{N}$ Bonds Angew. Chem., Int. Ed. 2012, 51, 12102-12106.

[7] Keyvanloo, K.; Mardkhe, M.K.; Alam, T.M.; Bartholomew, C.H.; Woodfield, B.F.; Hecker, W. C. Supported iron Fischer-Tropsch catalyst: superior activity and stability using a thermally stable silica-doped alumina support. ACS Catalysis 2014, 4, 1071-1077.

[8] Klettlinger, J.L.S. Fischer-Tropsch Cobalt Catalyst Improvements with the Presence of $\mathrm{TiO}_{2}, \mathrm{La}_{2} \mathrm{O}_{3}$, and $\mathrm{ZrO}_{2}$ on an Alumina Support. PhD diss., University of Akron, 2012.

[9] Suh, D.J.; Park, T.J.; Kim, J.H.; Kim, K.L. Fast sol-gel synthetic route to high-surface-area alumina aerogels. Chem. Mater. 1997, 9, 1903-1905. 
[10] Gauthier, B.M.; Bakrania, S.D.; Anderson, A.M.; Carroll, M.K. A Fast Supercritical Extraction Technique for Aerogel Fabrication. J. Non-Cryst. Solids 2004, 350, 238.

[11] Carroll, M.K.; Anderson, A.M.; Gorka, C.A. Preparing Silica Aerogel Monoliths Via a Rapid Supercritical Extraction Method. J. Visualized Exp. 2014, 84, e51421.

[12] Bono, M.S.; Anderson, A.M.; Carroll, M.K.; Alumina Aerogels Prepared via Rapid Super-critical Extraction. J. Sol-Gel Sci. Technol. 2010, 53, 216-226.

[13] Dunn, N.J.H.; Carroll, M.K.; Anderson, A.M. Characterization of alumina and nickel-alumina aerogels prepared via rapid supercritical extraction. Polymer Preprints 2011, 52, 250-251.

[14] Juhl, S.J.; Dunn, N.J.H.; Carroll, M.K.; Anderson, A.M.; Bruno, B.A.; Madero, J.E.; Bono, M.S. Epoxide-assisted alumina aerogels by rapid supercritical extraction. J. Non-Cryst. Solids 2015, $426,141-149$.

[15] Bruno, B.A.; Madero, J.E.; Juhl, S.J.; Rodriguez, J.; Dunn, N.J.H; Carroll, M.K.; Anderson, A.M. Alumina Based Aerogels as Three-Way Catalysts. Presented at the Ninth International Congress on Catalysis and Automotive Pollution Control (CAPoC9), August 2012.

[16] Smith, L.C.; A.M. Anderson; M.K. Carroll Preparation of vanadia-containing aerogels by rapid supercritical extraction for applications in catalysis. J. Sol-Gel Sci. Technol. 2016, 77, 160-171.

[17] Bruno, B.A.; Anderson, A.M.; Carroll, M.K.; Swanton, T.; Brockmann, P.; Palace, T.; Ramphal, I.A. Benchtop Scale Testing of Aerogel Catalysts: Preliminary Results. SAE Technical Paper No. 2016-01-0920 2016

[18] Maciver, D.S.; Tobin, H.H.; Barth, R.T. Catalytic aluminas I. Surface chemistry of eta and gamma alumina. J. Catal. 1963, 2, 485-497.

[19] Deraz, N.M.; Fouda, M.M.G. Synthesis, Structural, Morphological Properties of Cobalt-Aluminum Nano-Composite. Int. J. Electrochem. Sci 2013, 8, 2756-2767. 
[20] Du, P.; Kokhan, O.; Chapman, K.W.; Chupas, P.J.; Tiede, D.M., Elucidating the domain structure of the cobalt oxide water splitting catalyst by X-ray pair distribution function analysis. J. Am. Chem. Soc. 2012, 134, 11096-11099.

[21] Baumann, T.P.; Gash, A.E.; Chinn, S.C.; Sawvel, A.M.; Maxwell, R.S.; Satcher, Jr., J.H., Synthesis of High-Surface-Area Alumina Aerogels without the Use of Alkoxide Precursors. Chem. Mater. 2005, 17, 395-401.

[22] Oliveira, H.A.; Franceschini, D.F.; Passos, F.B. Cobalt Catalyst Characterization for Methane Decomposition and Carbon Nanotube Growth. J. Braz. Chem. Soc. 2014, 25, 2339-2349.

[23] Abad-Elwahad, S.M.; Bukhzam, A.F.; Mekhemer, G.A. Surface Characterization and Catalytic Activity for Alumina-Supported Cobalt Acetate. Am. J. Mater. Sci. 2015, 5, 6-9.

[24] Li, D.Y.; Lin, Y.S.; Li, Y.C.; Shieh, D.L.; Lin, J.L. Fabrication of Pseudoboehmite and Alumina: Effects of Water and 1-Hexadecyl-2, 3-dimethyl-imidazolium Chloride. Microporous Mesoporous Mater. 2007, 108, 276-282.

[25] Lian, J.; Ma, J.; Duan, X.; Kim, T.; Li, H.; Zheng, W. One-step ionothermal synthesis of $\gamma-\mathrm{Al}_{2} \mathrm{O}_{3}$ mesoporous nanoflakes at low temperature. Chem. Commun. 2010, 46, 2650-2652.

[26] Santos, P.S.; Santos, H.S.; Toledo, S.P. Standard Transition Aluminas. Electron Microscopy Studies. Mater. Res. 2000 3, 104-114.

[27] Glaspell, G. P.; Jagodzinski, P.W.; Manivannan, A. Formation of cobalt nitrate hydrate, cobalt oxide, and cobalt nanoparticles using laser vaporization controlled condensation. J. Phys. Chem. B 2004, 108, 9604-9607.

[28] Kim, K.S.; Park, Y.J. Catalytic properties of $\mathrm{Co}_{3} \mathrm{O}_{4}$ nanoparticles for rechargeable Li/air batteries. Nanoscale Res. Lett. 2012, 7, 1-6.

[29] Shriver, D.; Atkins, P. Inorganic Chemistry, 4th edition. London: Oxford University Press, 2006.

[30] Cui, H.; Zayat, M.; Levy, D. Sol-gel synthesis of nanoscaled spinels using propylene oxide as a gelation agent. J. Sol-Gel Sci. Technol. 2005, 35, 175-181. 
[31] Srisawad, N.; Chaitree, W.; Mekasuwandumrong, O.; Praserthdam, P.; Panpranot, J. Formation of $\mathrm{CoAl}_{2} \mathrm{O}_{4}$ Nanoparticles via Low-Temperature Solid-State Reaction of Fine Gibbsite and Cobalt Precursor. J. Nanomater. 2012, 95.

[32] Dhak, D.; Pramanik, P. Particle Size Comparison of Soft-Chemically Prepared Transition Metal (Co, Ni, Cu, Zn) Aluminate Spinels. J. Am. Ceram. Soc. 2006, 89, 1014-1021.

[33] Badkar, P.A.; Bailey, J.E. The mechanism of simultaneous sintering and phase transformation in alumina. J. Mater. Sci. 1976, 11, 1794-1806.

[34] Krokidis, X.; Raybaud, P.; Gobichon, A.E.; Rebours, B.; Euzen, P.; Toulhoat, H.; Theoretical study of the dehydration process of boehmite to $\gamma$-alumina. J. Phys. Chem. B 2001, 105, 5121-5130.

[35] Dynys, F.W.; Halloran, J.W. Alpha alumina formation in alum-derived gamma alumina. J. Am. Ceram. Soc. 1982, 65, 442-448.

[36] Wang, J.A.; Bokhimi, X.; Morales, A.; Novaro, O.; Lopez, T.; Gomez, R. Aluminum local environment and defects in the crystalline structure of sol-gel alumina catalyst. J. Phys. Chem. B 1999, 103, 299-303.

[37] Heywood, J.B. Internal Combustion Engine Fundamentals. New York: McGraw Hill, 1988.

[38] Omata, K.; Takada, T.; Kasahara, S.; Yamada, M. Active site of substituted cobalt spinel oxide for selective oxidation of $\mathrm{COH}_{2}$. Part II. Appl. Catal., A 1996, 146, 255-267.

[39] Xie, X.; Li, Y.; Liu, Z.Q.; Haruta, M.; Shen, W. Low-temperature oxidation of CO catalysed by $\mathrm{Co}_{3} \mathrm{O}_{4}$ nanorods. Nature 2009, 458, 746-749.

[40] Corrias, A.; Casula, M.F.; Ennas, G.; Marras, S.; Navarra, G.; Mountjoy, G. X-ray absorption spectroscopy study of $\mathrm{FeCo}-\mathrm{SiO}_{2}$ nanocomposites prepared by the sol-gel method. J. Phys. Chem. B 2003, 107, 3030-3039.

[41] Ji, L.; Lin, J.; Zeng, H.C. Metal-support interactions in $\mathrm{Co} / \mathrm{Al}_{2} \mathrm{O}_{3}$ catalysts: a comparative study on reactivity of support. J. Phys. Chem. B 2000, 104, 1783-1790. 
[42] Piao, L.; Chen, J.; Li, Y. Carbon nanotubes via methane decomposition on an alumina supported cobalt aerogel catalyst. China Particuol. 2003, 1, 266-270.

[43] Zawadzki, M.; Walerczyk, W.; López-Suárez, F.E.; Illán-Gómez, M.J.; Bueno-López, A. $\mathrm{CoAl}_{2} \mathrm{O}_{4}$ spinel catalyst for soot combustion with $\mathrm{NOx} / \mathrm{O}_{2}$. Catal. Commun. 2011, 12, 1238-1241.

[44] Teng, Y.; Sakurai, H.; Ueda, A.; Kobayashi, T. Oxidative removal of CO contained in hydrogen by using metal oxide catalysts. Int. J. Hydrogen Energy 1999, 24, 355-358. 